\title{
SMART PIG NUTRITION: EFFECT OF PIGLET WEANING NUTRITION STRATEGY ON THEIR GROWTH ABILITY, SURVIVAL AND ECONOMICS
}

\author{
Manfred Schönleben ${ }^{1}$, Joachim Mentschel², Sebastian Feser ${ }^{3}$, \\ Luboš Střelec ${ }^{1}$, Klaus Klunker ${ }^{4}$ \\ ${ }^{1}$ Department of Statistics and Operation Analysis, Faculty of Business and Economics, Mendel University in Brno, \\ Zemědělská 1, 61300 Brno, Czech Republic \\ ${ }^{2}$ Department of Global Business Development, Sano - The Animal Nutritionists, Grafenwald 1, 84180 Loiching, \\ Germany \\ ${ }^{3}$ Veterinary Health Department, Sano - The Animal Nutritionists, Grafenwald 1, 84180 Loiching, Germany \\ ${ }^{4}$ Monogastric Veterinary Health Department, Sano - Moderná výživa zvierat s.r.o., Dlhé diely I 23A, 84104 \\ Bratislava-Karlova Ves, Slovakia
}

Link to this article: https://doi.org/10.11118/actaun202068040699

Received: 16. 5. 2020, Accepted: 17. 6. 2020

To cite this article: SCHÖNLEBEN MANFRED, MENTSCHEL JOACHIM, FESER SEBASTIAN, STŘELEC LUBOŠ, KLUNKER KLAUS. 2020. Smart Pig Nutrition: Effect of Piglet Weaning Nutrition Strategy on Their Growth Ability, Survival and Economics. Acta Universitatis Agriculturae et Silviculturae Mendelianae Brunensis, 68(4): 699-705.

\begin{abstract}
Modern high-performance swine genetics, such as Danish hybrid sows, can yield large litter sizes. Especially in the suckling phase, managing these large litters with low piglet losses is often a challenge. To support the modern highly prolific sows and litters, the use of pre-starters as suckling pig supplementary feed, including sufficient freshwater access, are nowadays good professional practices. Neonatal piglets especially profit from liquid supplemental feed via the possible higher absolute dry matter intake potential, in comparison to solid feed or without supplement. Various studies also indicate that supplying additional liquid feed to piglets pre- and post-weaning may yield epigenetic, life-long positive effects in animal key performance indicators.

Although the advantages of early liquid piglet nutrition are today widely known, supplying adequate nutrient concentrations, the smooth preparation of the piglet's digestive system towards solid, starchy feed, and consequently enzymatic training to reduce post-weaning stress are still challenges which have to be considered.

Due to their higher concentration of solids, piglet starters in porridge form i.a. offer the advantage of higher nutrient densities and aggregation stability.

The aim of this study was, therefore, to answer the questions: 1) Can improved litter performance also routinely be obtained by supplying a porridge supplemental diet to neonatal piglets, and 2) Does improved litter performance translate into overall improved net economic returns within a professional piglet production setup of 254 piglets from 21 litters?

Results show, applying the preweaning porridge strategy not only yielded around 10\% higher daily gains and life weight results than conventional approaches, but also a return of investment of $2: 1$.
\end{abstract}

Keywords: neonatal piglets, porridge, liquid diet, weaning strategy, weight gain, economics

\section{INTRODUCTION}

Modern high-performance swine genetics, such as Danish hybrid sows, can yield large litter sizes. Especially in the suckling phase, managing these large litters with low piglet losses and adequate growth is often a challenge. Common 
challenges attributed to large litter sizes are a higher variance of life born piglets birth weights, a higher percentage of lightweight piglets, and therefore a reduced competitiveness of piglets in feed intake (Nevrkla et al., 2017). Partly due to these stressors, the gross of neonatal piglet losses commonly occur within the first three days, up to two weeks postpartum, dominated by crushing or overlay, hypoglycemia, but also bacterial and viral infections (McOrist, 2014; Alonso-Spilsbury et al., 2007). The primary nutrient source for the neonatal piglet is the milk of the sow (NRC, 2012). During lactation, sows with large litters therefore have a tremendous energy and protein requirement for milk production. They have to consume large quantities of nutrient and energy-dense feed, also to prevent excessive weight losses, responsible for fertility disorders and heat problems. To support the modern highly prolific sows and litters, the use of pre-starters as suckling pig supplementary feed, including sufficient freshwater access are nowadays good professional practice (Fraser et al., 1988; Close and Cole, 2003). Supplementing highly digestible starter feed to neonatal piglets may reduce the risk of losing light piglets, and yield a better growth and overall homogeneity of the litter. Neonatal piglets especially profit from liquid supplemental feed via the possible higher absolute dry matter intake potential, in comparison to solid feed or without supplement (Zijlstra et al., 1996). Various studies also indicate that supplying additional liquid feed to piglets pre- and post-weaning may yield epigenetic, life-long positive effects in animal key performance indicators, e.g., improved daily weight gains and shorter time to market intervals (Choct et al., 2004; Azain et al., 1996). Within the nutrient supply of neonatal piglets, two main aspects of taking advantage of epigenetic effects may be distinguished. Firstly, the immunological and nutritional benefits of high quantities and qualities of sow milk and supplementary feed sources (Kirchgeßsner et al., 2008; NRC, 2012), and secondly, the adequate supply of milk-borne developmental signal molecules (e.g., natural steroids), commonly exclusively via the sow's milk, termed the lactocrine hypothesis (Barotl et al., 2008; Bagnell et al., 2009; Bagnell and Bartol, 2019).

Although the advantages of early liquid piglet nutrition are widely known today, supplying adequate nutrient concentrations, the smooth preparation of the piglet's digestive system towards solid, starchy feed and consequently enzymatic training to reduce post-weaning stress still are challenges which have to be considered (Metzler and Mosenthin, 2007).

In contrast to liquid supplemental feed for preweaned piglets like milk replacers, porridgelike supplementary feeds have recently gained importance. Due to their higher concentration of solids, piglet starters in porridge form offer the advantage of higher nutrient densities and aggregation stability. Additionally, the reduced spillage of porridge type piglet starters may provide an additional economic benefit, in comparison to starters in liquid form.

The aim of this study was, therefore, to answer the questions: 1) Can improved litter performance also routinely be obtained by supplying a porridge supplemental diet to neonatal piglets, and 2) Does improved litter performance translate into overall improved net economic returns within a professional piglet production setup? Key performance indicators and rearing performance of 254 piglets from 21 litters were evaluated within 11 weeks postpartum, applying three different early nutrition and weaning strategies (dry, porridge, and gel).

\section{MATERIALS AND METHODS}

\section{Experimental Farm and Trial Design}

In this study, the litters of 21 lactating Danbred hybrid genetics sows were randomly assigned to three different supplementary feeding strategies before and during the weaning process (dry, porridge, and gel).

The animals were housed at a professional breeding sow farm near Straubing in Lower Bavaria within the same farrowing and later flat deck nursery department. All sows received the same standard lactation diet, following good professional practice. All piglets had ad libitum access to fresh water via one installed piglet cup system within all farrowing pens. Animal care and husbandry were conducted following the European Commission directive 2010/63/EU on the protection of animals used for scientific purposes.

\section{Weaning Nutrition Strategies}

After supplying adequate colostrum quantity to the newly born piglets (trial day 0), average weight littermates of large litters were evenly spread across the sows to achieve an average number of 12 piglets per sow. All piglets were weighed individually on the first day after birth, piglet sex (female, male) was assessed, and ear tags numbered for individual identification during the trial. At trial day three, the individual litter feed supplementation strategies commenced. Fig 1. gives an overview of the three nutritional weaning strategies. Starting with day three postpartum, the piglets received the randomly assigned treatments (dry, porridge, and gel).

The dry strategy includes the feeding of a piglet starter in meal form, supplying $20.0 \%$ crude protein (CP), $2.0 \%$ crude fiber (CF), and $11.5 \%$ ether extract (EE) at $92 \%$ dry matter (DM). Starting from day 21 , a 50:50 mix between the piglet starter and the mealy weaning starter was offered. Three days pre-weaning the piglets received 100\% weaning starter $(17 \% \mathrm{CP}, 3.5 \% \mathrm{CF}, 4 \% \mathrm{EE}$ at $92 \% \mathrm{DM})$. The supplementary diets within the farrowing department were supplied ad libitum for all litters 


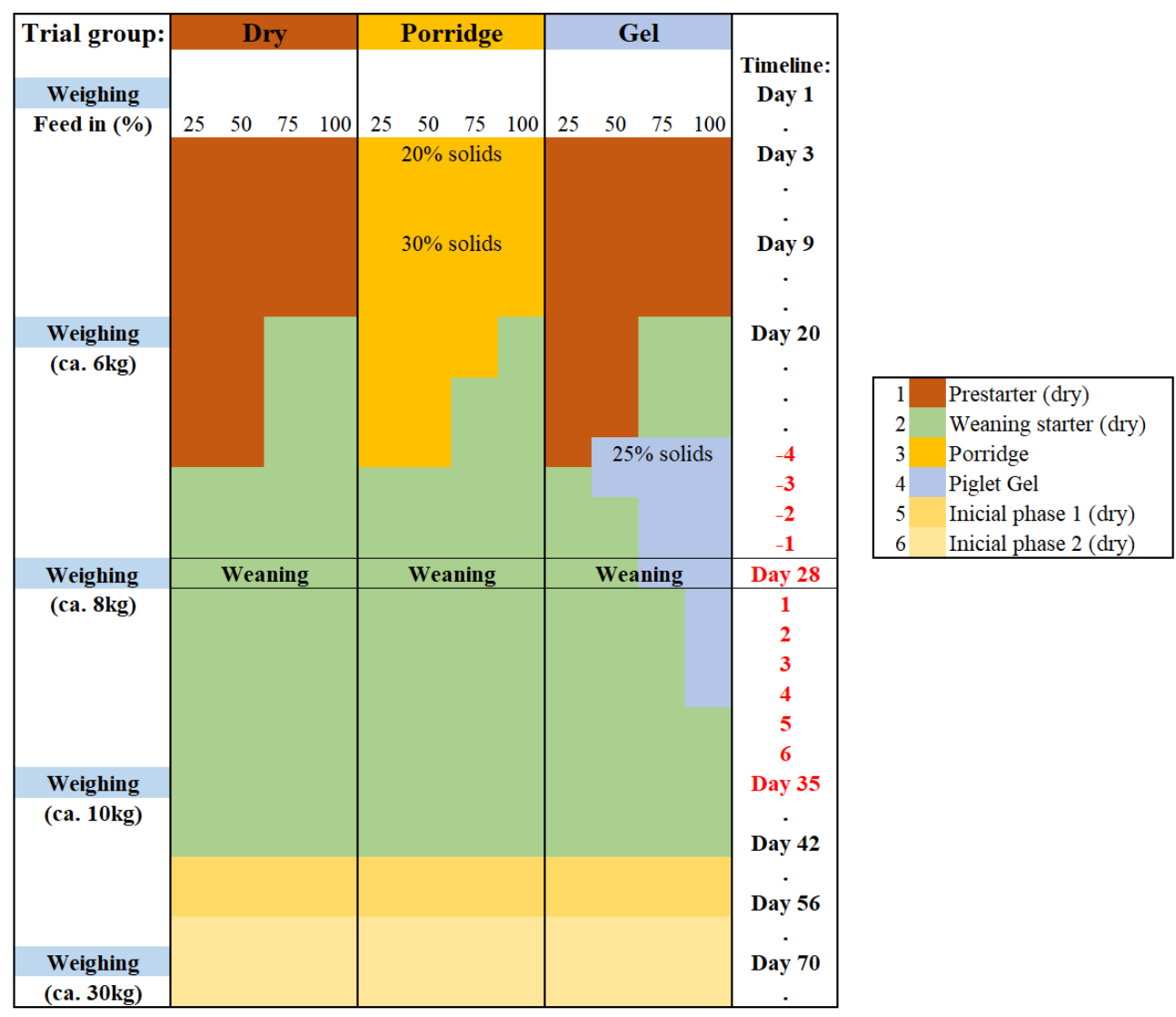

1: Graphical representation of supplementary piglet nutrition strategies, focusing on suckling, weaning, and flat deck nursery phases. Color codes indicate the applied product or feed mixture; blending steps (25, 50, 75, and 100\%) indicate the proportion of the supplied diet on a dry matter basis.

via stainless steel 21 volume round feeders. Weighing of the consumed diet and resupply of the respective diets was conducted each day at 6 AM for all litters.

Dietary supply for the litters receiving the porridge treatment started with 100\% porridge with 20\% solids (DM) supplying 3.8\% CP, 0.05\% CF, 2.2\% EE on as fed basis. At day nine, the density of the solids was raised to $30 \%$ within the porridge treatment groups, supplying $5.7 \% \mathrm{CP}, 0.1 \% \mathrm{CF}, 3.4 \%$ EE on as fed basis. Starting from day 20, porridge was supplied in a 75:25 ratio with weaning starter, and at day 22 in a 50:50 ratio. Three days pre-weaning $100 \%$ weaning starter diet was supplied. Dietary supply for the litters within the gel treatment group was conducted similarly to the dry treatment group, diverging four days pre-weaning with the application of 25\% 50:50 piglet starter and weaning starter mix, combined with $75 \%$ gel starter, on dry matter basis. The gel product was characterized by $3.1 \%$ CP, $0.5 \%$ CF, 2.2\% EE and 25\% DM. Two days before weaning, the gel treatment group received 50\% weaning starter $+50 \%$ gel and after weaning $75 \%$ weaning starter $+25 \%$ gel till the fourth day in the flat deck nursery. Starting from the fifth day in the flat deck, all treatment groups received the same diet. The weaning starter diet was followed by an initial phase 1 diet at day 43 and subsequently by an initial phase 2 diet starting at day 57. Single piglet weighing was conducted on three dates in the farrowing department (first-day postpartum, day 20, and weaning), and on two dates in the flat deck (day 35 and day 70).

After weaning at four weeks (28 days), 60 randomly selected piglets per treatment group were randomly assigned to one of four housing units within the same flat deck nursery. The surplus piglets were housed together in the fourth flat deck nursery compartment and no longer considered within the study. Piglets surpassing a bodyweight of $25 \mathrm{~kg}$ are subsequently termed grower pigs, and after the final weighing at day 70 (flat deck), the now grower pigs were marketed to a professional fattening farm.

\section{Economics Measurement and Survival}

The income over feed cost (IOFC) as an important indicator of the economic efficiency of piglet rearing was applied. All grower pigs within the trial were marketed to a fattening unit at a base price of $87 € / 30 \mathrm{~kg}$ grower pig. The IOFC per grower pig was calculated, following:

$I O F C=\gamma \times \mu-\delta$,

where: $\gamma$ is the grower pig weight in $\mathrm{kg}, \mu$ the $\mathrm{kg}$ price in $€$, and $\delta$ the accumulated dietary costs per grower pig in $€$. To assess the dietary costs per 
grower pig, the feed consumption per litter was multiplied by the respective dietary investment. To account for lower (higher) than average individual grower pig weights, the kg price is adjusted within a bonus/malus context (grower pigs lighter than $27.5 \mathrm{~kg}$ are discounted by $-2 €$, grower pigs heavier $35 \mathrm{~kg}$ only receive a bonus of $0.5 €$ per additional $\mathrm{kg}$ life weight). Required agricultural commodity prices were obtained following board of trade information. Survival data was assessed by counting the piglets/ grower pigs at each weighing date. All phenotypic analyses were performed using $\mathrm{R}$ ( $\mathrm{R}$ Core Team, 2018). To account for a higher probability of Type-1 errors due to multiple comparisons, the applied pairwise t-tests were Bonferroni corrected, by testing the individual $\mathrm{P}$ values by the quotient of the significance level (alpha) and the number $(n)$ of pairwise comparisons (alpha/n).

\section{RESULTS}

\section{Growth Performance and Piglet Survival}

The number of piglets per sow among treatment groups did not differ significantly $(\mathrm{P}>0.05)$. Arithmetic mean of birth weights between treatment groups dry, gel, and porridge was not significantly different, averaging at $1,456 \mathrm{~g} \pm 100 \mathrm{~g}$ (Tab. I, Fig. 2). Life weight development of piglets measured in weeks three and four showed numerically superior values for the porridge treatment, followed by the gel and dry treatment groups. Daily weight gains of piglets in the suckling phase averaged at $197 \mathrm{~g}$ (dry), $209 \mathrm{~g}$ (gel), and $228 \mathrm{~g}$ (porridge), with significantly $(\mathrm{P}<0.05)$ higher daily gains within the porridge treatment. Supplementary feed consumption within the farrowing department was highest for the porridge group, followed by the gel group and dry group (Tab. I). Due to crushing and overlay, five piglets were lost in treatment

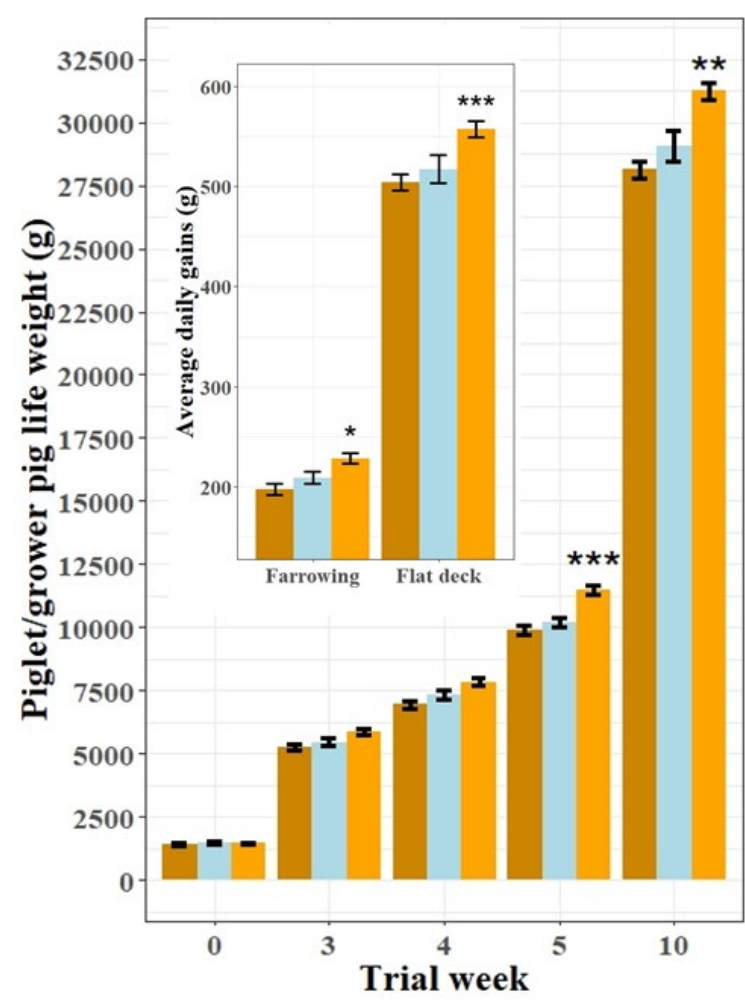

Concepts: $\square$ Dry $\square$ Gel $\square$ Porridge

2: Piglet life weight development (average daily gains) of treatment groups dry, gel, and porridge, stratified by trial week (nursing department). Whiskers show the respective standard error of the mean (*, $P<0.05$; ** $P<0.01$; ***, $P<0.001$; Bonferroni corrected).

I: Key performance indicators, number of piglets/grower pigs ( $n$ ), dry matter (DM) consumption, and monetary results, stratified by treatment group $\left({ }^{*}, P<0.05 ;{ }^{* *}, P<0.01\right.$; ***, $\left.P<0.001 ; n s, P>=0.05\right)$

\begin{tabular}{lccc}
\hline \multicolumn{1}{c}{ Observation/Treatment } & Dry & Gel & Porridge \\
\hline Average birth weight (g) & 1,408 & 1,481 & 1,450 \\
Postpartum (n) & 86 & 84 & 84 \\
Week 3 (n) & 81 & 74 & 79 \\
Weaning (n) & 81 & 74 & 79 \\
Market (n) & 60 & 60 & 60 \\
Farrowing department feed consumption (kg DM/piglet) & 5.4 & 5.5 & 7.9 \\
Flat deck feed consumption (kg DM/grower pig) & 35.54 & 37.35 & 38.08 \\
Flat deck feed conversion & 1.67 & 1.72 & 1.62 \\
Total dietary cost (€/piglet) & 21.23 & 25.96 & 26.64 \\
Base price (€/30kg) & 87.00 & 87.00 & 87.00 \\
Income (€/grower pig) & 80.95 & $83.87^{* *}$ & $90.64^{* * *}$ \\
IOFC (€/grower pig) & 59.72 & $57.91^{\text {ns }}$ & $64.00^{* * *}$ \\
Advantage (€/grower pig) & -0.83 & $-2.64^{\mathrm{ns}}$ & $3.46^{* * *}$ \\
\hline
\end{tabular}


groups dry and porridge, respectively, ten in treatment group gel, amounting to a total of $8.5 \%$ pre-weaning piglet losses. No animal losses were registered during the feeding experiment within the flat deck phase. Life weight development of weaned piglets in the flat deck, measured one week (week five) and six weeks (week ten) post-weaning showed significantly $(\mathrm{P}<0.001$ and $\mathrm{P}<0.01)$ higher values for the porridge treatment, followed by the gel and dry treatment groups (Fig. 2). Daily weight gains of the weaned piglets averaged at $504 \mathrm{~g}$ (dry), $517 \mathrm{~g}$ (gel), and $557 \mathrm{~g}$ (porridge), with significantly $(\mathrm{P}<0.001)$ higher daily gains within the porridge treatment. Flat deck feed consumption was highest for the porridge group, followed by the gel and dry group (Tab. I).

\section{Economic Performance Assessment}

Dietary investment costs per piglet differed between treatment groups and were highest for the porridge treatment, followed by gel and dry treatment groups (Tab. I). Within week ten the porridge treatment group reached significantly highest $(\mathrm{P}<0.001)$ average life weights $(31.26 \mathrm{~kg})$ and average income per grower pig (90.64 €/grower pig), followed by the gel (29.07 kg; 83.87 €/grower pig, $\mathrm{P}<0.01)$ and the dry treatment group $(28.14 \mathrm{~kg}$;

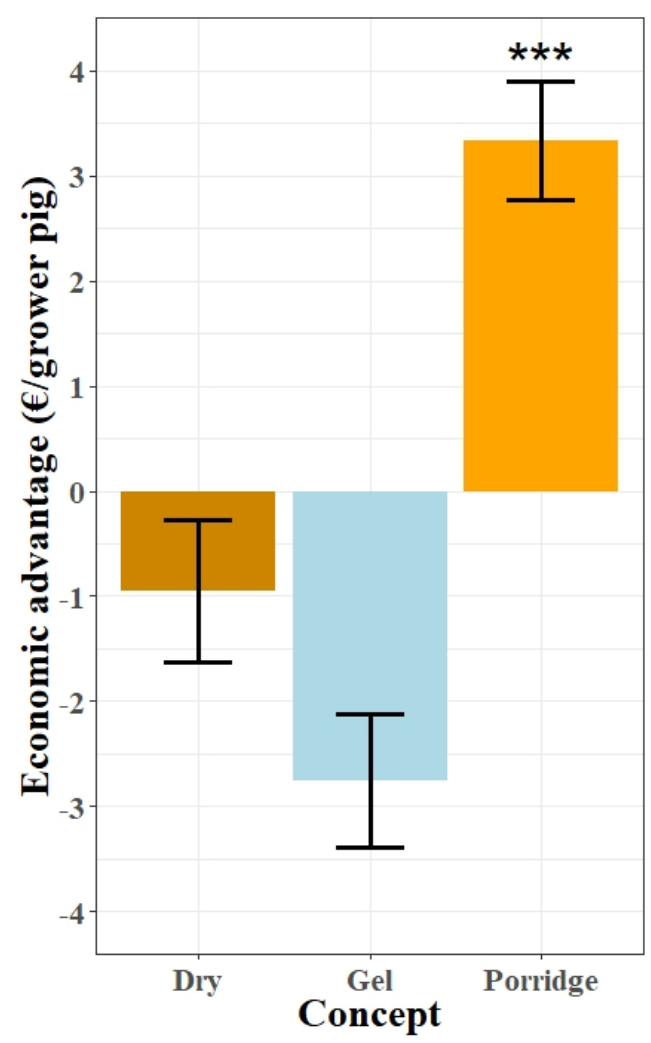

3: Relative advantage of treatment groups dry, gel and porridge, over the arithmetic mean income over feed cost (IOFC) in Euros per grower pig (,$P<0.05$; **, $P<0.01$; *** $P<0.001$; Bonferroni adjusted). Whiskers show the respective standard error of the mean.
$80.95 €$ /grower pig). Significantly $(\mathrm{P}<0.001)$ highest income over feed cost (IOFC) results were observed within the porridge treatment (64.00 €/grower pig), followed by the dry (59.72 €/grower pig) and gel treatment group (57.91 €/grower pig). Relative advantage of IOFC in € per grower pig was the largest $(\mathrm{P}<0.001)$ for the porridge group (basis arithmetic mean of treatment group IOFC results), followed by the dry, and gel treatment group (Tab. I, Fig. 3).

\section{DISCUSSION}

As weaning constitutes a sudden and drastic physiological event in piglet nursing, pre-weaning supplemental nutrition seems to pose an enormous window of opportunity to positively shape also long-term life and production phase-related key performance indicators (KPI). It is meanwhile commonly acknowledged that a sufficient supplementary nutrient supply for the piglets within the first weeks of life may yield positive effects for the piglets and the highly prolific sow alike (Nevrkla et al., 2017; Kirchgeß̂ner et al., 2008; Bagnell and Bartol, 2019). While piglet supplemental feed in dry form may be easy to apply, studies have shown that piglets may profit from higher feed intakes and higher daily gains when supplied supplemental feed in liquid form (Zijlstra et al., 1996). Within this study, absolute feed intake and daily gains within pre-weaned piglets corroborate the results of Zijlstra et al. (1996), Odle and Harrell (1998), and Choct et al. (2004). Daily weight gains of the porridge fed piglets were with $228 \mathrm{~g} / \mathrm{d}$, significantly higher $(+12.3 \%)$, than the average daily gains of their trial mates within the dry and gel groups.

Interestingly, the apparent carry over effects within the porridge treatment group. Results suggest a continuous advantage in average daily weight gains (+9\%) and life weight development, measured in the first $(+14.1 \%)$ and sixth week $(+9.3 \%)$ post-weaning, in comparison to the average gel and dry treatment group performances. As expected, the applied gel product showed numerical advantages, in contrast to the dry strategy in terms of post-weaning weight gains and life weight development. This suggests that the gel strategy may be efficient in partly mending weaning stress. Nonetheless, the performance differences in daily weight gains and life weight development may also be explained by numerically larger birth weights and a slightly lower average number of piglets per sow within the gel treatment group. The larger variance of life weight results at the end of the trial also corroborates this conclusion.

Of specific practical importance may be the observation that a successful weaning preparation strategy might be achieved well before the actual weaning date. The porridge strategy with early supplementation of nutrients apparently elicited 
epigenetic effects, effective far beyond the actual feeding period. Since all treatment groups had access to sow milk, and a similarly reduced stress environment at weaning (no feed change), the obtained results point into this direction (AlonsoSpilsbury et al., 2007; Barotl et al., 2008). In light of the favorable results obtained within the porridge treatment group, the question, whether improved litter performance may also routinely be obtained by supplying a porridge supplemental diet to neonatal piglets can be answered with yes.

Of similar importance as the biological KPIs are economical KPIs for the practitioner. Does improved litter performance also translate into overall improved net economic returns? As expected, the treatment groups gel and porridge require a higher investment into feed and also feed preparation. Therefore not only the higher monetary investment may be considered, but also potential higher requirements in working hours. Despite yielding higher market prices for the grower pigs in comparison to the dry group, the gel group generated the lowest income over feed cost results. In combination with potential higher time requirements, therefore the gel strategy may be first seen as a niche weaning option. In contrast to the gel and dry methods, the porridge treatment not only yielded the highest grower pig market prices, but also the highest IOFC per grower pig. The higher monetary investment of $\sim 5 €$ /pre-weaned piglet of the porridge diet in comparison to the dry diet was paid back by $10 €$ /grower pig improved market return. Therefore within the presented trial, a return of investment of 2:1 to the advantage of the porridge strategy can be stated. With the nowadays available cup systems, group farrowing and smart herd management approaches, the edge of a porridge strategy may be further supported, due to an additional reduction of the associated workload (Mesarec et al., 2020; Schönleben et al., 2020). The obtained results are, therefore, highly encouraging towards improving economic, as well as biological outcomes in professional piglet production.

\section{CONCLUSION}

In summary, the presented results from a representative commercial piglet nursery unit suggest that piglet growth can be substantially supported by supplying a porridge pre-weaning diet in the early suckling phase. With the availability of automatic/semi-automatic liquid feeding systems (e.g., cup systems and milk/porridge taxis), the application of liquid to porridge-like feeds within farrowing units seems, therefore, to be a straight forward and economical procedure, also under practical field conditions. For instance, the application of a porridge taxi may constitute an easy to implement, economically attractive investment also for small and medium-sized practitioners and piglet producers. The readily prepared porridge may then be efficiently supplied to the piglets e.g. via a dosing lance and $~ 21$ stainless steel round feeders within the farrowing department. This way, animal control and supplementary feeding of the neonatal piglets can be combined within one step. Aiming for a 30\% total solids concentration of the piglet porridge (300 $\mathrm{g}$ of product dissolved in $700 \mathrm{~g}$ of water) throughout its application period may constitute an additional relief for the practitioner. Since supplementary feed intake of the piglets within the first week postpartum is lowest by experience, the transition from a once per day porridge feeding strategy towards two or multiple times per day may be conducted starting from the second week postpartum. Higher feed intake at early stages, accelerated growth rates, reduced days to market, and improved income over feed cost are among the advantages, practical piglet producers may profit from, in feeding supplementary porridge diets. The results suggest, the detected edges may not only manifest within the nursery but also carry over into grower and fattening phases.

\section{Acknowledgements}

The authors thank the Sano Academy, Sano - The Animal Nutritionists, and especially Fam. Martin Baran for their highly appreciated help, logistics, product, and raw material support. We also thank a commercial animal nutrition company for supporting the gel product and two unknown reviewers for their appreciated and constructive feedback.

\section{REFERENCES}

ALONSO-SPILSBURY, M., RAMIREZ-NECOECHEA, R., GONZALEZ-LOZANO, M. et al. 2007. Piglet survival in early lactation: A review. J. Anim. Vet. Adv., 88(8): 2767-2778.

AZAIN, M. J., TOMKINS, T., SOWINSKI, J. S. et al. 1996. Effect of supplemental pig milk replacer on litter performance: Seasonal variation in response. Journal of Animal Science, 74(9): 2195-2202.

BAGNELL, C. A. and BARTOL, F. F. 2019. Relaxin and the 'Milky Way': The lactocrine hypothesis and maternal programming of development. Molecular and Cellular Endocrinology, 487: 18-23. 
BAGNELL, C. A., STEINETZ, B. G., and BARTOL, F. F. 2009. Milk-borne relaxin and the lactocrine hypothesis for maternal programming of neonatal tissues. In: Relaxin and related peptides: Fifth interntional conference. New York: New York Academy of Sciences, pp. 152-157.

BAROTL, F. F., WILEY, A. A. and BEGNELL, C. A. 2008. Epigenetic programming of porcine endometrial functon and the lactocrine hypothesis. Reproduction in Domestic Animals, 43(2): 273-279.

CHOCT, M., SELBY, E. A., CADOGAN, D. J. et al. 2004. Effects of particle size, processing, and dry or liquid feeding on performance of piglets. Australian Journal of Agricultural Research, 55(2): 237-245.

CLOSE, W. H. and COLE, D. A. 2003. Nutrition of sows and boars. Nottingham, UK: Nottingham University Press.

FRASER, D., PHILLIPS, P. A., THOMPSON, B. K. et al. 1988. Use of water by piglets in the first days after birth. Canadian Journal of Animal Sience, 68(3): 603-610.

KIRCHGEßSNER, M., ROTH, F. X., SCHWARZ, F. J. et al. 2008. Animal nutrition [in German: Tierernährung]. $12^{\text {th }}$ Edition. Frankfurt am Main: DLG-Verlags-GmbH.

MCORIST, S. 2014. Baby piglet problems. In: Pig disease identification and diagnosis guide. Walllingford, UK: CAB International, pp. 91-117.

MESAREC, N., PAČNIK, U., MESARIČ, A. et al. 2020. The effect of eocialising piglets during lactation on performance, suckling behaviour and weaning aggression: A preliminary field study. Acta Univ. Agric. Silvic. Mendelianae Brun., 68(1): 73-79.

METZLER, B. and MOSENTHIN, R. 2007. Effects of organic acids on growth performance and nutrient digestibilities in pigs. In: LÜCKSTÄDT, C. (Ed.). Acidifiers in animal nutrition. Packington, UK. Context Products Ltd, pp. 39-54.

NEVRKLA, P., VÁCLAVKOVÁ, E., HADAŠ, Z. et al. 2017. Effect of birth weight of piglets on their growth ability, carcass traits and meat quality. Acta Univ. Agric. Silvic. Mendelianae Brun., 65(1): 119-123.

NRC. 2012. Nutrient requirements of swine. Washington, D.C.: National Academy Press.

ODLE, J. and HARRELL, R. J. 1998. Nutritional approaches for improving neonatal piglet performance: Is there a place for liquid diets in commercial production? A review. Asian-Australian Journal of Animal Sciences, 11(6): 774-780.

R CORE TEAM. 2018. $R$ : A language and environment for statistical computing. [Programme]. Vienna, Austria: R Foundation for Statistical Computing. Available at: http://www.R-project.org/ [Accessed: 2020, July 15].

SCHÖNLEBEN, M., MENTSCHEL, J. and STŘELEC, L. 2020. Towards smart dairy nutrition: Improving sustainability and economics of dairy production. Czech Journal of Animal Science, 65(5): 153-161.

ZIJLSTRA, R. T., WHANG, K., EASTER, R. A. et al. 1996. Effect of feeding a milk replacer to earlyweaned pigs on growth, body composition, and small intestinal morphology compared with suckled littermates. Journal of Animal Science, 74(12): 2948-2959.

Contact information

Manfred Schönleben: manfred.schoenleben@googlemail.com

Joachim Mentschel: j.me@sano.de

Sebastian Feser: Sebastian.Feser@sano.de

Luboš Střelec: lubos.strelec@mendelu.cz

Klaus Klunker: Klunker.Klaus@gmail.com 